\title{
EVOLUÇÃO DA PRODUÇÃO ACADÊMICA SOBRE A EDUCAÇÃO AMBIENTAL NA UNIVERSIDADE TECNOLÓGICA FEDERAL DO PARANÁ (UTFPR)
}

\author{
Ronualdo Marques ${ }^{1}$ \\ Carlos Eduardo Fortes Gonzalez ${ }^{2}$ \\ Claudia Regina Xavier ${ }^{3}$
}

Resumo: Nesta pesquisa são apresentados os resultados da análise da produção acadêmica e da inserção da Educação Ambiental (EA) na Universidade Tecnológica Federal do Paraná (UTTFPR). Teve por objetivo apresentar como se caracteriza a Educação Ambiental como campo de conhecimento e produção acadêmica na Universidade Tecnológica Federal do Paraná. Metodologicamente, trata-se de uma pesquisa de natureza quali-quantitativa com análise bibliométrica a partir do método estatístico descritivo. Detectou-se um crescimento significativo da Educação Ambiental na última década, com o advento das pesquisas mostrando um indicativo para a consolidação da EA na UTFPR e para o alinhamento com as tendências de pesquisas no Brasil.

Palavras-chave: Educação Ambiental; Temática Ambiental; UTFPR; Produção Acadêmica.

Abstract: This research presents the results of the analysis of academic production and the insertion of Environmental Education (EE) at the Federal Technological University of Paraná (UTFPR). It aimed to present how Environmental Education is characterized as a field of knowledge and academic production at the Federal Technological University of Paraná. Methodologically, it is a quali-quantitative research with bibliometric analysis based on the descriptive statistical method. A significant growth of Environmental Education was detected in the last decade, with the advent of research showing an indication for the consolidation of environmental education at UTFPR and for alignment with research trends in Brazil.

Keywords: Environmental Education; Environmental Thematic; UTFPR; Academic Production.

\footnotetext{
${ }^{1}$ Universidade Tecnológica Federal do Paraná. E-mail: ronualdo.marques@gmail.com, Lattes: <http://lattes.cnpq.br/1134226964905219 >

2 Universidade Tecnológica Federal do Paraná,. E-mail: cefortes@utfpr.edu.br, Lattes: <http://lattes.cnpq.br/8289557565668912 >

${ }^{3}$ Universidade Tecnológica Federal do Paraná,. E-mail: cxavier@utfpr.edu.br, Lattes: <http://lattes.cnpq.br/5220557381173979 >.
}

Revbea, São Paulo, v.16, № 1: 66-77, 2021. 


\section{Introdução}

No Brasil, a Educação Ambiental (EA) ainda busca seu reconhecimento efetivo para sua implementação em todos os níveis de ensino. Os desafios relacionados ao reconhecimento estão essencialmente associados à política adotada no Brasil, principalmente na década de 90 , que se pautou na execução de um estado mínimo e na submissão da nossa sociedade às regras impostas pelo mercado econômico e pelo capitalismo desenfreado (MORADILLO; OKI, 2004). É importante ressaltar, que mesmo tendo todo o amparo legal onde a Educação Ambiental ser reconhecidamente importante para o estudo das relações homem, sociedade e natureza, colocado como interdisciplinar e ainda como um tema transversal, "a sua presença ainda é inexpressiva nos currículos" (MARQUES; GONZALEZ; XAVIER, 2017).

Neste mesmo período a EA no Brasil estreou com o desenvolvimento de pesquisa associada a diversas publicações oriundas dos trabalhos acadêmicos vinculados à titulação acadêmica, seja lato-sensu ou stricto-sensu. Nas décadas anteriores as ações eram caracterizadas pela inexistência de referenciais teóricos adequados disponíveis, onde muitas das publicações eram traduções estrangeiras feitas pelos escassos profissionais qualificados na área (SATO; SANTOS, 2003).

A EA enfatiza durante o processo de ensino e aprendizagem a relação entre sujeito e meio ambiente e entre sociedade e a natureza; sua definição abrange a compreensão da relação educação, sociedade e meio ambiente. Os limites da capacidade de suporte e a recuperação do meio ambiente ainda estão entre os grandes desafios da sociedade. Aqui se evidenciam os papéis da ação educativa e da pesquisa, orientadas para o ambiente (JACOBI, 2003).

Desta forma, o desenvolvimento de pesquisas a fim de compreender a evolução das produções acadêmicas em EA e ações que contribuíram para o crescimento desta área é muito importante. Segundo Lima (2005) a "Educação Ambiental apresenta-se como um campo em crescimento e multidimensional ainda insuficientemente explorado em sua complexidade, diversidade, em sua(s) identidade(s) e alcance social' (LIMA, 2005, p. 11).

A crise do conhecimento científico exige um novo papel da universidade. Assim, as instituições universitárias são convocadas a assumirem um posicionamento reflexivo e crítico, a fim de construir uma racionalidade que induza à transformação de paradigmas científicos tradicionais e a promover novos conhecimentos e integração de diferentes saberes, com a participação da sociedade (GUIMARÃES, 2012).

Para tal exigência, necessita-se problematizar a própria organização do pensamento e da instituição universitária sobre a necessidade da constante modificação. Morin (2002) aponta para a necessidade de se pensar a reforma universitária como reforma de pensamento, no sentido de formar cidadãos capazes de enfrentar os problemas sociais, ambientais do seu tempo. Deste 
modo, não se pode reformar somente a instituição se as mentes não forem também reformadas.

A universidade, como instituição de investigação e centro de Educação técnica e superior tem papel essencial na reconfiguração de mundo e, portanto, deve assumir a responsabilidade maior no processo de produção e incorporação da dimensão ambiental nos sistemas de Educação e formação profissional. Deve também propiciar aos profissionais e educadores ambientais fundamentos teórico-práticos indispensáveis para compreender, analisar, refletir e reorientar seu fazer profissional numa perspectiva ambiental que promova a transformação social e que sensibilize para a tomada de consciência sobre os problemas ambientais a partir das responsabilidades individuais e coletivas por ações e atitudes que não contribuem para a preservação ou mudanças significativas para a recuperação do ambiente.

\section{Um pouco mais sobre a Universidade Tecnológica Federal do Paraná}

Segundo o site institucional da UTFPR (2019) esta teve sua origem com a Escola de Aprendizes Artífices, fundada em 1909; a UTFPR herdou uma longa e expressiva trajetória na educação profissional. Das diferentes denominações à Universidade Tecnológica Federal do Paraná: 1909 - Escola de Aprendizes Artífices do Paraná; 1937 - Liceu Industrial do Paraná; 1942 Escola Técnica de Curitiba; 1959 - Escola Técnica Federal do Paraná; 1978 Centro Federal de Educação Tecnológica do Paraná- CEFET-PR (LEITE, 2010).

Em 07 de Outubro de 2005 o então CEFET-PR passou à condição de Universidade Tecnológica Federal do Paraná (UTFPR) e mantém o principal foco na Graduação, pós-graduação e a extensão (BRASIL, 2005). Oferece mais de 100 cursos superiores entre tecnologia, bacharelados (entre eles engenharias) e licenciaturas. Também se promovem cursos de qualificação profissional de nível médio; a UTFPR oferta 19 cursos técnicos em diversas áreas do mercado, como técnicos de nível médio integrado e cursos técnicos de nível médio subsequente na modalidade à distância (UTFPR, 2019).

A consolidação do ensino de graduação conduz ao crescimento da pós-graduação, a qual está em expansão, com a oferta de mais de 90 cursos de especialização, 51 programas de pós-graduação stricto-sensu, com cursos de mestrado e doutorado, além de centenas de grupos de pesquisa.

A UTFPR tem treze Câmpus distribuídos no Estado do Paraná, possuindo grande abrangência no Estado conforme a Figura 01. Cada Câmpus mantém cursos planejados de acordo com a necessidade da região onde está situado. Em 2018/2019, os colaboradores da UTFPR somavam 2840 professores e 1182 técnico-administrativos. O número de estudantes regulares nos cursos técnicos, graduação e pós-graduação passam de 34 mil (UTFPR, 2019). 


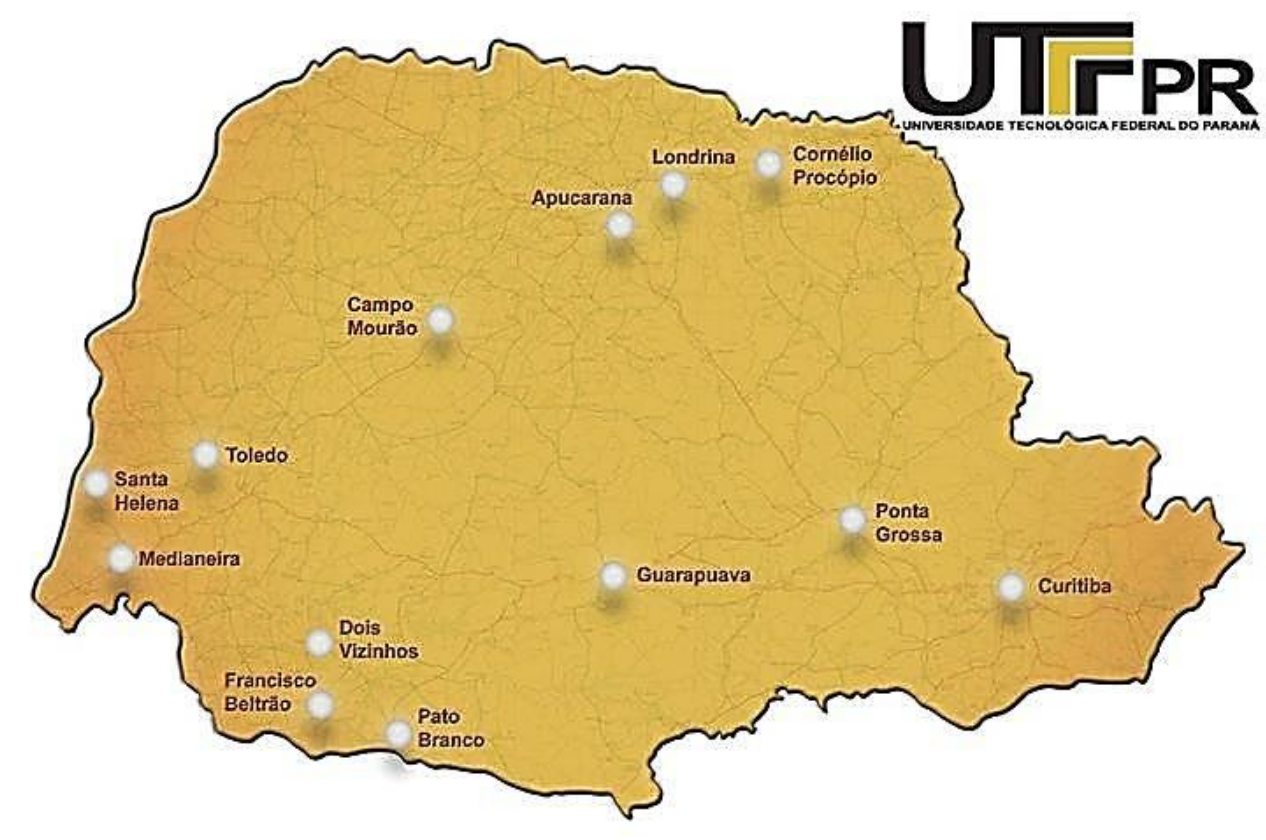

Figura 1: Distribuição da Universidade Tecnológica Federal no Paraná.

Fonte: Portal Institucional da UTFPR.

A UTFPR tem como missão desenvolver a Educação tecnológica de excelência por meio do ensino, pesquisa e extensão, interagindo de forma ética, sustentável, produtiva e inovadora com a comunidade para o avanço do conhecimento e da sociedade. Tem como visão ser modelo educacional de desenvolvimento social e referência na área tecnológica (UTFPR, 2019).

Nesse interim, apontamos algumas indagações que adotamos como problemática: De que forma a Educação Ambiental está adentrando os diferentes níveis de ensino na Universidade Tecnológica Federal do Paraná? Como se configura a Educação Ambiental na produção acadêmica da UTFPR?

\section{Metodologia}

Nesta pesquisa optou-se por um estudo estatístico que se preocupou com a representatividade da produção em EA na UTFPR. Segundo Cooper e Schindler (2003), uma pesquisa descritiva. É uma análise bibliométrica, quantificando a produção científica e sua disseminação (MARTINS, 2008). De acordo com Leite Filho (2006) indicadores de desempenho bibliométricos são úteis para avaliar a pesquisa acadêmica, bem como orientar rumos e estratégias de financiamentos de pesquisas.

Tomou-se por referência de consulta o Portal de Informação em Acesso Aberto (PIAA, 2019) por ser a ferramenta que promove o acesso e visibilidade das produções acadêmicas da Universidade Tecnológica Federal 
do Paraná - UTFPR. Intentou-se responder, neste recorte proposto, o que a UTFPR produziu no campo da Educação Ambiental e disponibiliza em seus repositórios. Tratou-se de um questionamento que exigiu a abordagem qualiquantitativa para responder.

Inicialmente para justificar a Educação Ambiental como campo de conhecimento da Educação, utilizou-se análise documental como complemento a pesquisa bibliográfica para delinear o histórico da Educação Ambiental desde sua gênese em nível de Brasil, trazendo os elementos que marcam sua presença no marco da lei e suas sucessões em formulações de leis, decretos, diretrizes e políticas para a expansão da Educação Ambiental nos sistemas de ensino. A pesquisa documental "toma como fonte de coleta de dados documentos, escritos o que se denomina de fontes primárias" (MARCONI; LAKATOS, 2017); elaborados como finalidades diversas, tais como assentamento, autorização e comunicação etc. Assim, justifica a análise documental nessa pesquisa por ser considerado um material consultado interno à organização com documento institucional oferecendo resultados lógicos (GIL, 2017).

O levantamento do corpus para a análise seguiu uma delimitação e seleção rigorosa (MORAES, 2003), com a busca feita no PIAA utilizando os termos "Educação Ambiental" ou "Temática Ambiental" nos campos "Título", "Assunto" ou "Resumo" em que se procuraram sistematicamente pelos termos desde a criação do PIAA em 2009 até o ano de 2019. Foi obtido um total de 445 trabalhos publicados em Educação Ambiental num total de 17.564 trabalhos acadêmicos publicados na UTPFR e que se encontram disponíveis no PIAA. A partir desses critérios os resumos selecionados foram agrupados de acordo com os seguintes descritores: Ano da produção e Nível Acadêmico.

A preocupação em organizar os dados quantitativamente e com razoável grau de precisão requer o método estatístico descritivo, seguindo os passos de coleta de dados, crítica de dados, apuração dos dados, exposição ou apresentação dos dados, análise dos resultados. Segundo Gil (2017, p. 17). Com esse método, as informações coletadas são registradas como variáveis determinadas em termos numéricos, configurando uma metodologia favorável para esse tipo de pesquisa. A pesquisa ao PIAA é compreendida como um procedimento bibliográfico que, de acordo com Gil (2017, p. 50), oferece vantagens por poder cobrir uma maior quantidade de dados, caso desta pesquisa, que se ocupa em abranger alta dispersão de dados entre o tempo e bibliotecas.

\section{Resultados e Discussão}

Iniciou-se a pesquisa construindo a problemática, a partir dos dados históricos da implementação de Políticas Públicas sobre a Educação Ambiental em documentos oficiais referentes à inserção da EA no Brasil (BRASIL, 1981; 1988; 1998; 1999; 2002; 2012), o que permite compreender melhor as tendências das pesquisas em Educação Ambiental no Brasil.

Revbea, São Paulo, v.16, № 1: 66-77, 2021. 
Destacou-se alguns documentos oficiais promulgados no Brasil que tratam sobre a Educação Ambiental:

a) Lei Federal ํo. 6938 de 1981, que estabelece a Política Nacional do Meio Ambiente, na qual a Educação Ambiental é situada como um dos componentes que contribui na solução dos problemas ambientais, sendo ofertada a todos os níveis e modalidades de ensino;

b) Promulgação da Constituição Federal em 1988, que seu Art. 225, \& 10, inciso $\mathrm{VI}$, determina que a Educação Ambiental juntamente com a promoção da conscientização social para defesa do meio ambiente é dever do Poder Público, indicando que as lutas de classe estavam refletindo nas decisões dos Constituintes;

c) Aprovação dos Pareceres no. 04/98 e o $n^{0}$. 15/98 do Conselho Nacional da Educação, que por sua vez, estabelecem as Diretrizes Curriculares Nacionais para o Ensino Fundamental e Médio;

d) Lei oㅗ. 9795/99/DOU institui a Política Nacional de Educação Ambiental e o Decreto no. 4281/02 regulamenta a referida Lei.

e) Aprovação da Resolução n.o 02 de 15 de junho de 2012, que estabelece as Diretrizes Curriculares Nacionais para a Educação Ambiental, reconhecendo a relevância e obrigatoriedade da Educação Ambiental em todos os níveis e modalidades de ensino (MARQUES; RAIMUNDO; XAVIER, 2019, p. 450).

Como se buscava compreender as potencialidades do campo da Educação Ambiental na Universidade Tecnológica Federal do Paraná, com base na problemática: "Quais são as referências à Educação Ambiental e à temática ambiental nas produções acadêmicas na Universidade Tecnológica Federal do Paraná?" optou-se pelo plano de trabalho que segundo Gil (2017) consiste inicialmente na busca de palavras-chave; tal busca deu-se no PIAA/UTFPR. Inicialmente as expressões escolhidas para busca foram "Educação Ambiental" e "Temática Ambiental"; tendo sido encontradas 445 referências com os títulos e assuntos selecionados.

$\mathrm{Na}$ Tabela 1 é apresentada a frequência das 445 referências encontradas com os títulos descritores desde a criação do Portal de Informação em Acesso Aberto da UTFPR - PIAA até 2019. 
Tabela 1: Produção acadêmica em Educação Ambiental na Universidade Tecnológica Federal do Paraná de 2003 a 2019.

\begin{tabular}{cc}
\hline ANO & QUANTIDADE \\
\hline 2003 & 1 \\
2004 & 0 \\
2005 & 0 \\
2006 & 1 \\
2007 & 3 \\
2008 & 3 \\
2009 & 2 \\
2010 & 7 \\
2011 & 10 \\
2012 & 22 \\
2013 & 31 \\
2014 & 57 \\
2015 & 112 \\
2016 & 40 \\
2017 & 92 \\
2018 & 52 \\
2019 & 12 \\
TOTAL & 445 \\
\hline
\end{tabular}

Fonte: Portal de Informação em Acesso Aberto da UTFPR (PIAA).

Após a seleção do corpus de análise por ano, pôde-se observar que não houve produções acadêmicas divulgadas no meio digital anteriormente a 2003 nos repositórios da Universidade Tecnológica Federal do Paraná (UTFPR). Para confirmar os dados levantados fez-se uma leitura e análise sistemática dos títulos, resumo, palavras-chaves e assunto atestando sua veracidade no campo das produções acadêmicas na UTFPR referentes à Educação Ambiental e à Temática Ambiental ano a ano sistematicamente.

Ao destacarem-se as produções acadêmicas no repositório da Universidade Tecnológica Federal do Paraná entre os anos de 2003 a 2019, encontra-se na produção geral um total de 17562 publicações. A Educação Ambiental corresponde aproximadamente a $2,54 \%$ das produções acadêmicas na UTFPR.

A partir dos critérios com os seguintes descritores: "ano da produção e nível acadêmico" as produções acadêmicas foram selecionadas e agrupadas para mostrar a representatividade e como vem se construindo o campo de pesquisa dentro da Universidade Tecnológica Federal do Paraná.

$\mathrm{Na}$ Tabela 2 são mostradas as produções acadêmicas por ano de produção e por nível acadêmico. 
Tabela 2: Produções em Educação Ambiental para diferentes níveis acadêmicos na Universidade Tecnológica Federal do Paraná de 2003 a 2019.

\begin{tabular}{ccccccc}
\hline Ano & Graduação & Especialização & Artigo & Dissertação & Tese \\
\hline 2003 & - & - & 1 & - & - \\
\hline 2004 & - & - & - & - & - \\
2005 & - & - & - & - & - \\
2006 & - & - & 1 & - & - \\
2007 & - & - & 3 & - & - \\
2008 & - & - & 3 & - & - \\
2009 & - & - & 2 & - & - \\
2010 & - & - & 7 & - & - \\
2011 & - & - & 9 & 1 & - \\
2012 & 12 & - & 6 & 4 & - \\
2013 & 8 & 3 & 12 & 8 & - \\
2014 & 10 & 30 & 11 & 5 & 1 \\
2015 & 13 & 74 & 12 & 13 & - \\
2016 & 10 & 2 & 19 & 9 & - \\
2017 & 10 & 28 & 41 & 13 & - \\
2018 & 3 & - & 39 & 10 & - \\
2019 & - & - & 12 & - & - \\
TOTAL & 66 & 137 & 63 & 1 \\
\hline
\end{tabular}

Fonte: Portal de Informação em Acesso Aberto da UTFPR (PIAA).

Os dados apresentados na Tabela 2 revelam o panorama das 445 produções acadêmicas na Universidade Tecnológica Federal do Paraná. Com base nestes dados tem-se que os artigos em Revistas Científicas da UTFPR assumem uma posição de destaque na totalidade das produções acadêmicas visto que este meio de divulgação corresponde a $40 \%$ (178) da produção acadêmica no campo da Educação Ambiental. No entanto, pode-se apontar que os artigos não são oriundos somente de resultados de pesquisas realizadas nos diferentes níveis acadêmicos da UTFPR, mas também de fontes externas que buscaram os periódicos da instituição para divulgar suas pesquisas.

A Especialização no nível acadêmico de Pós-Graduação lato-sensu ocupou o segundo lugar com um total de 30,8\% (137) monografias registradas no PIAA - UTFPR sobre Educação Ambiental até 2019. Em seguida tem-se a Graduação com 14,8\% (66) da produção acadêmica, o mestrado com 14,1\% (63) das produções e por fim se encontrou $0,2 \%$ (1) de teses doutorais no mesmo período. 
De acordo com a Tabela 2 observa-se em 2012 o surgimento da primeira divulgação de Trabalhos de Conclusão de Curso (TCC) com 12 trabalhos que são oriundos da primeira turma de Tecnologia e Gestão Ambiental no Câmpus de Medianeira. Em 2014 e 2015 se vê uma variação no campo da Especialização que mostra em 2014 um total de 30 monografias e em 2015 subiu para 74, esse acréscimo significativo corresponde ao término das primeiras turmas dos cursos de Especialização em Ensino de Ciências e do curso de Gestão Ambiental no município de Medianeira. Em 2017 houve (28) monografias referentes à segunda turma que concluiu a Especialização em Gestão Ambiental no Câmpus de Medianeira da UTFPR.

A partir dos dados apresentados que se referem à produção acadêmica na UTFPR sobre a Educação Ambiental e a temática ambiental traçou-se um perfil de pesquisas no Mestrado considerando que esse nível acadêmico é consolidado na instituição. Nesse contexto, foram apresentadas no Quadro 1 as referências e frequência dos termos encontrados na análise de dados desta pesquisa.

Quadro 1: Frequência de Referências a Educação Ambiental e a Temática Ambiental

\begin{tabular}{|c|c|c|c|}
\hline \multicolumn{2}{|c|}{ Temática Ambiental } & \multicolumn{2}{|l|}{ Ensino } \\
\hline Referência & Frequência & Referência & Frequência \\
\hline - Meio Ambiente & 11 & - Práticas Pedagógicas & 8 \\
\hline \multirow{2}{*}{$\begin{array}{l}\text { - Compostagem } \\
\text { - Espaços sustentáveis } \\
\text { - Saúde }\end{array}$} & \multirow[t]{2}{*}{3} & - Formação docente & 7 \\
\hline & & - Representações sociais & 6 \\
\hline \multirow{4}{*}{$\begin{array}{l}\text { - Área de Proteção } \\
\text { Ambiental } \\
\text { - Desenvolvimento } \\
\text { Sustentável } \\
\text { - Agroecologia } \\
\text { - Problemas } \\
\text { socioambientais } \\
\text { - Áreas verdes } \\
\text { - Jardim sensorial } \\
\text { - Agrotóxicos } \\
\text { - Assentamento de } \\
\text { Reforma Agrária } \\
\text { - Unidades de } \\
\text { Conservação } \\
\text { - Preservação } \\
\text { - Diagnóstico Ambiental } \\
\text { - Impactos Ambientais } \\
\text { - Meio Rural } \\
\text { - Terras Indígenas } \\
\text { - Chuva Ácida }\end{array}$} & \multirow[t]{4}{*}{1} & $\begin{array}{l}\text { - Interdisciplinaridade } \\
\text { - Tecnologia } \\
\text { - Sensibilização }\end{array}$ & 4 \\
\hline & & $\begin{array}{l}\text { - Projetos } \\
\text { - Percepção Ambiental } \\
\text { - Ambiente virtual de } \\
\text { aprendizagem }\end{array}$ & 3 \\
\hline & & $\begin{array}{l}\text { - Temas Geradores } \\
\text { - Aprendizagem significativa } \\
\text { - Lúdico }\end{array}$ & 2 \\
\hline & & $\begin{array}{l}\text { - Experimentação } \\
\text { - CTS } \\
\text { - Modelagem Matemática } \\
\text { - Tema Transversal } \\
\text { - Currículo } \\
\text { - Educação em solos } \\
\text { - Sequências Didáticas } \\
\text { - Jogos Educativos } \\
\text { - Avaliação } \\
\text { - Responsabilidade social } \\
\text { - Ecoformação } \\
\text { - Materiais Didáticos }\end{array}$ & 1 \\
\hline
\end{tabular}

Continua... 
continuação.

\begin{tabular}{|c|c|c|c|}
\hline \multicolumn{2}{|c|}{ Temática Ambiental } & \multicolumn{2}{|l|}{ Ensino } \\
\hline \multicolumn{2}{|l|}{ Água } & \multicolumn{2}{|l|}{ Resíduos } \\
\hline Referência & Frequência & Referência & Frequência \\
\hline $\begin{array}{l}\text { - Conservação de } \\
\text { Recursos Hídricos }\end{array}$ & 4 & - Resíduos Sólidos & 8 \\
\hline - Saneamento & 2 & $\begin{array}{l}\text { - Resíduos Orgânicos } \\
\text { - Reciclagem }\end{array}$ & 2 \\
\hline $\begin{array}{l}\text { - Tratamento de esgoto } \\
\text { - Disponibilidade de água } \\
\text { - Qualidade de água } \\
\text { - Pegada Hídrica }\end{array}$ & 1 & $\begin{array}{l}\text { - Coleta Seletiva } \\
\text { - Pilhas e Baterias } \\
\text { - Resíduos de Construção e } \\
\text { demolição } \\
\text { - Gerenciamento de Resíduos }\end{array}$ & 1 \\
\hline \multicolumn{2}{|c|}{ Leis - Órgãos - Gestão } & \multicolumn{2}{|l|}{ Educação } \\
\hline Referência & Frequência & Referência & Frequência \\
\hline - Políticas Públicas & 2 & - Educação Ambiental & 33 \\
\hline \multirow{5}{*}{$\begin{array}{l}\text { - Análise jurídica } \\
\text { - Direito Ambiental } \\
\text { - Rede de Proteção } \\
\text { Animal } \\
\text { - Sec. Munic. de Educação } \\
\text { - Sec. Munic. de Meio } \\
\text { Ambiente } \\
\text { - Documentos oficiais } \\
\text { - Agenda } 21 \\
\text { - Legislação } \\
\text { - Administração Pública } \\
\text { - Gestão Urbana } \\
\text { - Gestão Socioambiental } \\
\end{array}$} & \multirow[t]{5}{*}{1} & - Ensino de Ciências & 8 \\
\hline & & - Ensino Fundamental & 6 \\
\hline & & - Ensino de Química & 5 \\
\hline & & - Educação Infantil & 2 \\
\hline & & $\begin{array}{l}\text { - Escola de Campo } \\
\text { - Educação Não-Formal } \\
\text { - Ensino Médio } \\
\text { - Ensino Superior }\end{array}$ & 1 \\
\hline
\end{tabular}

Fonte: Portal de Informação em Acesso Aberto da UTFPR (PIAA).

Conforme o Quadro 1, buscou-se nas dissertações as referências e frequências relacionadas à "Educação Ambiental" e "Temática Ambiental" no qual foram exibidas as expressões mais utilizadas e que demonstram quais foram as tendências de pesquisa neste campo do conhecimento na Universidade Tecnológica Federal do Paraná. Tem-se que a primeira dissertação defendida foi em 2006 no Programa de Pós-Graduação em Tecnologia e Sociedade - PPGTE no Câmpus Curitiba e divulgada no PIAA em 2011 e que teve como objetivo discutir as correlações entre pressupostos da Educação Ambiental e a coleta seletiva de resíduos sólidos.

Os dados foram divididos por categorias, sendo: "Temática Ambiental"; "Ensino"; "Água"; "Resíduos"; "Leis, órgãos e Gestão" e "Educação" na qual se apresentaram esses indicadores com referências e as frequências encontradas nas expressões utilizadas que dão representatividade as pesquisas.

$\mathrm{Na}$ categoria "Temática Ambiental" a expressão mais utilizada foi: "Meio Ambiente" com 5,55\% (11). Na categoria de "Ensino", "Práticas 
Pedagógicas" com 4,04\% (8); Na categoria "Água" a expressão mais frequente foi "Conservação dos Recursos Hídricos" com 2,02\% (4). Na produção associada aos "Resíduos" a mais encontrada foi "Resíduos Sólidos" com 4,04\% (8). Na categoria "Leis, órgãos e Gestão" a mais encontrada foi "Políticas Públicas" com 1,01\% (2) e na categoria "Educação", "Educação Ambiental" com $16,6 \%$ (33).

Assim, com o panorama das tendências de pesquisas em EA na UTFPR, nota-se que a produção acadêmica é diversificada e multifacetada e se atenta ao estudo de problemas locais, regionais e globais a fim de compreender e de buscar soluções para diminuir os impactos ambientais ao meio ambiente sejam eles de curto, médio ou logo prazo e tem-se que a Educação Ambiental é o meio mais assertivo para o processo de sensibilização e conscientização de todos para a preservação e o cuidado com o meio ambiente para as futuras gerações.

\section{Considerações finais}

Apesar de se constituir num campo de pesquisa em produção recente e por isso mesmo ainda não devidamente consolidada em todos os níveis acadêmicos é possível identificar que a produção acadêmica em EA está presente nos diversos cursos de graduação, especialização na UTFPR. Mesmo mostrando variações de ano por ano, temos que a pesquisa e a produção acadêmica tende a aproximar em suas pesquisas das temáticas relacionados a problemática ambiental visto que notoriamente vem aumentando significativamente nos últimos anos e a universidade é um lugar propício e que tem grande interesse em questões que contribuam para a evolução da ciência que dê respostas a sociedade pela sua contribuição social a fim de amenizar tais impactos na relação homem, sociedade e natureza.

Ao considerar-se o panorama das questões relativas à Educação Ambiental tem-se que a sua presença nas produções acadêmicas reflete uma maior preocupação e busca de conhecimentos relacionados à EA, evidenciados nas pesquisas desenvolvidas na UTFPR.

\section{Referências}

BRASIL. Dispõe sobre o Histórico da UTFPR. Disponível em: $<$ http://portal.utfpr.edu.br/institucional/sobre-a-utfpr-1>. 2019. Acesso em $18 \mathrm{de}$ Junho de 2020.

COOPER, D. R.; SCHINDLER, P. S. Métodos de pesquisa em administração. Trad. Luciana de Oliveira Rocha. 7. ed. Porto Alegre: Bookman, 2003.

GIL, A. C. Como elaborar projeto de pesquisa. 6. ed. São Paulo: Atlas, 2017. 
GUIMARÃES, S. S. Mo; INFORSATO, E. C. A percepção do professor de biologia e a sua formação: A Educação Ambiental em questão. Ciência \& Educação, v. 18, n. 3, p. 737-754, 2012.

JACOBI, P. Environmental education, citizenship and sustainability. Cadernos de Pesquisa, São Paulo v. 118, n. 1, p. 189-206, 2003.

MARCONI, M. A.; LAKATOS, E. M. Fundamentos de Metodologia Científica. 8. ed. São Paulo: Atlas, 2017.

LEITE FILHO, G. A. Padrões de Produtividade de Autores em Periódicos de Congressos na Área de Contabilidade no Brasil: Um Estudo Bibliométrico. Anais do Congresso USP de Controladoria e Contabilidade, 6, São Paulo: 2006. Anais do Congresso USP de Controladoria e Contabilidade. São Paulo, 2006.

LEITE, J. C. C. (org.). UTFPR: uma história de 100 anos. 2. ed. Curitiba: Ed. UTFPR, 2010.

LIMA, G. F. C. Formação e dinâmica do campo da Educação Ambiental no Brasil: Emergência, identidades, desafios. Tese de doutorado em Ciências sociais. Universidade Estadual de Campinas, 2005.

MARQUES, R; RAIMUNDO, J. A; XAVIER, C. R. Educação Ambiental: Retrocessos e contradições na Base Nacional Comum Curricular. Interfaces da Educação, v. 10, n. 28, p. 445-467, 2019.

MARQUES, R.; GONZALEZ, C. E. F.; XAVIER, C. R. As dificuldades da inserção e da prática em Educação Ambiental no currículo escolar. Anais do XVI Encontro Paranaense de Educação Ambiental. Curitiba: UFPR, 2017.

MARTINS, G. A. Estudo de Caso: Uma Estratégia de Pesquisa. São Paulo: Atlas, 2008.

MORADILLO, E. F.; OKI, M. C. M. Educação Ambiental na universidade: construindo possibilidades. Quim. Nova, Salvador, v. 27, n. 2, p.332-336, 2004.

MORAES, R. Uma tempestade de luz: a compreensão possibilitada pela análise textual discursiva. Ciência e Educação, Bauru - SP, v. 9, n. 2, p. 191211, 2003.

MORIN, E. A cabeça bem-feita: repensar a reforma, reformar o pensamento. Rio de Janeiro: Bertrand, 2002.

SATO, M.; SANTOS, J. E. Tendências nas pesquisas em Educação Ambiental. p. 253-283. In: NOAL, F.O.; BARCELOS, V.H.L. (orgs.). Educação Ambiental e Cidadania - cenários brasileiros. Santa Cruz do Sul: EDUNISC, 2003.

UTFPR. Portal de Informação em Acesso Aberto (PIAA). Disponível em: $<$ https://portaldeinformacao.utfpr.edu.br/>. Acesso em 15 de Junho de 2019. 